\title{
Formação da literatura brasileira: o pensamento dialético de Antonio Candido
}

\section{Formação da literatura brasileira: Antonio Candido dialectical thinking}

1 Licenciada em Espanhol e Inglês pela Universidad Pedagógica Nacional de Colombia, Mestre em Estudos Literários
pela Universidad Nacional de Colombia, Doutoranda do PPG História da Literatura pela Universidade Federal do Rio Grande FURG, Bolsista CAPES. ju_masan@hotmail.com
Yuly Paola Martínez Sánchez 1

RESUMO: 0 artigo propõe uma interpretação do trabalho Formaç̃o da literatura brasileira de Antonio Candido, ressaltando que o pensamento do crítico se debate entre a tradição das formas de fazer história literária, e as exigências teóricas e metodológicas de seu presente. Esse jogo dialético do pensamento de Candido fundamenta toda a construção e escrita desta história da literatura brasileira, pois as escolhas dos períodos, dos autores e as obras estão justificadas na relação dialética que eles revelam. 0 artigo ressalta a noção da literatura como sistema integrado no sistema cultural, social e até politico do país, porque dá um lugar relevante aos estudos de teoria, crítica e história literária, no sentido que permite-lhes ser reconhecidos nos estudos sociais como construtores de significado da sociedade.

PaLAVRAS-chavE: História da literatura brasileira; Antonio Candido, dialética.

ABSTRACT: This article proposes an interpretation to the work Formação da literatura brasileira by Antonio Candido, emphasizing on the critic thinking that debates between the tradition of how to do literary history, and the theoretical and methodological demands of Antonio Candido's present. This dialectic game of Candido thinking bases all the construction of this Brazilian literary history, since the choices of the periods, of the authors and the literary works are justified in the dialectic relation that they reveal. The article stands out the notion of literature as an integrated system in the cultural, social and political system of the country, because it gives an important place to the literary theory, critics and history, in the sense that permit them being recognized in the social studies as constructors of society sense.

KEYwoRDS: Brazilian literary history; Antonio Candido, dialectics.

Quem quiser ver em profundidade, tem que aceitar o contraditório [...] porque ele é o próprio nervo da vida (CANDIDO, 1993, p. 24) 
$A^{\prime}$

guns estudiosos da obra de Antonio Candido têm caracterizado a Formação da literatura brasileira (1993) como uma História das Ideias, no caso de Celia Pedrosa (1994), devido à integração que o crítico faz do pensamento dos intelectuais brasileiros do século XVIII e XIX. Ou, segundo Davi Arregucci Jr. (1992), um "livro de crítica, mas escrito de um ponto de vista histórico", pela presença do tom crítico na aproximação aos fenômenos literários vistos em série. Sem dúvida, o trabalho do crítico brasileiro pode ser enquadrado nas duas definições anteriores, porém a mais apropriada é a de uma história literária. O próprio autor deixa clara sua pretensão histórica ao nomear, no prefácio da $1^{\text {a }}$ edição, a História da Literatura Brasileira, de Silvio Romero, a Pequena História, de Ronald de Carvalho, e a História da Literatura Brasileira, de José Veríssimo, como fontes que inspiraram-lhe o interesse pelo estudo da formação da literatura brasileira:

[...] a História da Literatura Brasileira, de Sílvio Romero, [...] tendo sido dos livros que mais consultei entre os dez e quinze anos, à busca de excertos, dados biográficos e saborosos julgamentos do autor. Nele estão, provavelmente, as raízes do meu interesse pelas nossas letras. Li também muito a Pequena História, de Ronald Carvalho, pelos tempos do ginásio, reproduzindo-a abundantemente em provas e exames, de tal modo estava impregnado das suas paginas. Só mais tarde, já sem paixão de neófito, li a Historia, de José Veríssimo, provavelmente a melhor e, ainda hoje, mais viva de quantas se escreveram; a influência deste crítico, naqueles primeiros tempos em que se formam as impressões básicas, recebi-a através das varias séries dos Estudos de Literatura. (CANDIDO, 1993, p. 11)

A menção destas histórias literárias, como marcas significativas na sua formação acadêmica, dá um panorama ao leitor sobre o estilo e as ideias nas quais se desenvolve a Formação da Literatura Brasileira. De um lado, a História da Literatura Brasileira, de Sílvio Romero, influi especialmente no trabalho histórico de Candido pela associação estreita entre literatura e sociedade que Romero propicia, e que de certa maneira se correlaciona com a formação de Candido enquanto sociólogo. A história de Silvio Romero está enquadrada dentro dos "trabalhos cuja finalidade é estabelecer uma relação entre a Literatura e as condições sociais, tendentes a uma exposição paralela do social e do literário, normalmente propondo a existência de um nexo causal determinista entre ambos" (SOUZA, 1987, p. 71).

Por outro lado, a Pequena História da Literatura Brasileira, de Ronald de Carvalho, caracterizada como uma história literária muito ampla, ao contemplar fenômenos fora do campo literário, se faz importante pela proposta da formação do Brasil como sociedade partindo do corpus literário. “[A]través dessa obra é possível conhecer o que importava ao repertório intelectual do país, a ponto do seu autor produzir um painel interpretativo da sociedade brasileira marcado pelos ideais de modernização e nacionalidade" (ABREU, 2007, p. 268). Novamente o diálogo entre literatura e sociedade se faz presente nas influências teóricas de Candido, e agora acrescentando um propósito unificador de sociedade moderna e independente, da mão da literatura.

Finalmente, a História de Veríssimo, considerada pelo autor como a melhor de quantas se escreveram, é significativa para ele e para a historiografia da literatura no Brasil, porque:

procurou utilizar um critério que não limitasse o campo de atividade dos escritores à vida nacional, definindo: 'somente o escrito com o propósito ou a intuição dessa arte, isto é, com os artifícios de invenção e de composição que a constituem é, a meu ver, literatura'. Essa declaração demarcaria a separação entre literatura e sociologia e viria a inaugurar, no Brasil, a utilização de um critério estético que tem a prerrogativa sobre o de nacionalidade. (VIANA 2005, p. 31)

Assim, em contraposição com a corrente sociológica, na qual Antonio Candido se formou, encontra-se esta proposta a favor do texto literário como construção autônoma, que cria um equilíbrio entre suas referências 
no campo da história da literatura e nas escolhas metodológicas que aplica no seu trabalho.

As produções anteriores das histórias da literatura do Brasil me encaminham a ressaltar que "na História da Literatura cabe distinguir três diretrizes principais: a diretriz biográfico-psicológica, a sociológica e a filológica" (SOUZA, 1987, p. 64). O enfoque biográfico-psicologista predominou no século XIX e foi bastante discutido, e nos últimos tempos até rejeitado nos estudos literários, pois a obra literária, real objeto do campo, é às vezes ignorada pela predominância do escritor como o gênio criador. No caso da tendência sociológica, ao estabelecer uma relação entre a literatura e a sociologia, "nota-se o deslocamento de interesse da obra para os elementos sociais que formam a sua matéria, para as circunstâncias do meio que influíram na sua elaboração, ou para a sua função na sociedade" (SOUZA, 1987, p. 73). E por último, a diretriz filológica se propõe fazer a historiografia da literatura através da edição e da explicação de textos, o estudo das fontes e influências literárias, evitando a inserção de outras disciplinas alheias à literatura.

Não é demais afirmar que as Histórias de Sílvio Romero e Ronald de Carvalho se localizam basicamente na corrente sociológica, e a História de Veríssimo poderia enquadrar-se na diretriz filológica. À primeira vista, a Formação da Literatura Brasileira encontra-se num estado de oscilação entre uma e outra corrente, por isso ainda não poderia fechá-la numa tendência única. Desse modo, nas páginas seguintes, meu objetivo é fazer uma aproximação das formas e singularidades desta história da literatura brasileira, na tentativa de conseguir uma caracterização esclarecedora e propositiva do trabalho de Candido.

Numa primeira aproximação à Formação da Literatura Brasileira o leitor encontra-se com uma história literária aparentemente tradicional, pela importância dada pelo crítico às figuras individuais. A apresentação dos nomes dos escritores nos capítulos do livro e a inclusão de dados biográficos, que operam como explicação de algum aspecto da obra, são razões para pensar ou situar este estudo em uma tendência tradicional, ou seja, aquelas histórias literárias comuns no século XIX, com recorte biográfico-psicológico.

Um dos exemplos da presença desse tipo de estudo na Formação é a associação que o autor faz do local de nascimento e o lugar de formação dos poetas como influência na consolidação dos temas e formas de sua escrita poética. Tal é o caso de poetas como Cláudio Manoel da Costa que, segundo Candido, revela em sua obra um "contraste entre o rústico berço mineiro e a experiência intelectual e social da Metrópole, onde fez os estudos superiores e se tornou escritor" (1993, p. 86, v. 1), ou "Basílio da Gama e Silva Alvarenga, mineiros de nascimento, são cariocas pelo sentimento de água, das cores, exprimindo-se com certa macieza que nos faz imaginá-los nas sombras frescas do Passeio Público, envoltos no denso fascínio na natureza tropical" (1993, p. 105, v. 1). Outro exemplo é a inclusão do relato da vida amorosa de Tomás Gonzaga para explicar sua obra: "talvez a circunstância de namorar uma adolescente rica (ele, pobre e quarentão) tenha exacerbado esta tendência, que seria além disso exibicionismo compreensível de homem apaixonado" (1993, p. 118, v. 1). Marilia, nome poético da namorada e depois noiva, opera como uma presença física concretamente sentida e como pretexto poético de uma vaga pastorinha incaracterística.

Contudo, quando o leitor vai-se adentrando no caminho que Candido desenha, percebe a Formação da literatura brasileira como um trabalho distante da típica história literária de corte biográfico-psicológico. Aquela que expõe uma lista ou registro de autores e obras em ordem cronológica, em muitas ocasiões desligados. Esse mecanismo de associação da vida do autor com a obra não permanece em toda sua escrita, pelo contrário se alterna com análises formais ou estéticas, assim como com aproximações de tipo sociológico. Dessa forma, a abordagem das obras literárias se mantém num 
movimento constante, impedindo a inserção desta história literária num único marco ou método de análise:

Já se vê que, ao lado das considerações formais, são usadas aqui livremente as técnicas de interpretação social e psicológica, quando julgadas necessárias ao entendimento da obra; este é o alvo, e todos os caminhos são bons para alcança-lo, revelando-se a capacidade do crítico na maneira porque os utiliza, no momento exato e na medida suficiente. Há casos, por exemplo, em que a informação biográfica ajuda a compreender o texto; por que rejeitá-la, estribado em preconceito metodológico ou falsa pudicícia formalista? Há casos em que ela nada auxilia; por que recorrer obrigatoriamente a ela? (CANDIDO, 1993, p. 35, v. 1)

A junção de tendências, tidas como opostas, na interpretação das obras literárias, revela os traços de um pensamento complexo e orgânico em Antonio Candido, no sentido de que as obras só adquirem valor quando são estudadas na sua integridade. Essa integridade refere-se não só à coerência interna do texto, como também a fatores externos, como sua ligação com assuntos sociais e com as particularidades da vida do escritor.

Para o crítico brasileiro "a literatura é um conjunto de obras, não de fatores, nem de autores. Como, porém, o texto é a integração de elementos sociais e psíquicos, estes devem ser levados em conta para interpretá-lo" (CANDIDO, 1993, p. 34, v. 1). Sem dúvida, nesta ideia da Formação da Literatura Brasileira encontramos os rastros da influência dos historiadores da literatura brasileira já nomeados, e, sobretudo a apropriação teórica e crítica de Candido, que não se limita a seguir o caminho marcado pela tradição, pois propõe uma visão integradora de se aproximar à literatura, apagando as fronteiras entre uma e outra teoria e corrente metodológica.

Com esta proposta inovadora para a época, Antonio Candido parece cumprir com os pressupostos de Hélène Pouliquen, quem caracteriza ao historiador da literatura ideal para um novo leitor. Segundo a professora, as particularidades do trabalho histórico, como o estudo das fontes, das influências e a consecução ou ruptura dos modelos,

no exime al investigador del esfuerzo de plantear adecuadamente la dialéctica entre el texto y el extratexto y, sobre todo, no debe privarlo del placer de entender el funcionamiento de lo que es, también, el texto: una máquina, a la vez precisa y muy compleja, de producir sentido, a partir de un conjunto que le es extraño pero sin el cual no hubiera nacido. Un historiador de la literatura es ese investigador que aporta al lector menos informado que él, no "fuentes", "influencias" o "modelos", sino informaciones claves para esclarecer los polos extratextuales de interacción, presentes, de alguna manera, en el texto mismo, y que son la condición misma de la producción de sentido. (POULIQUEN, 2006 p. 386-387)

A exposição da dialética entre texto e extratexto, colocada por Pouliquen, enquanto uma operação primordial em qualquer história da literatura, é uma condição relevante na História de Candido, que se dá pela integração teórica e metodológica na interpretação das obras literárias. Contudo, é na verdade o caráter dialético dessa relação o que fundamenta a Formação, pois a literatura brasileira, conforme o crítico define, se constrói num movimento dialético entre o conhecimento e a consciência da existência de uma tradição, e a capacidade de integrar esteticamente o texto literário ao espírito do presente. Essa ligação dialética define a seleção de autores e obras, assim como os períodos abordados. De outro lado, o fato de chamar sua história literária por Formação da literatura brasileira também tem coerência com essa intenção de não enquadrar em estruturas fechadas e imóveis o estudo da literatura. 0 termo formação alude um processo em construção, ainda não concluído, que segue sua configuração ao ritmo do decorrer da história.

Outro assunto a levar em conta na escrita dialética desta história é a associação do trabalho de crítico literário com o de historiador da literatura. 
Antecipando-se aos pressupostos de Jauss (1967) a respeito da necessidade do historiador da literatura se reconhecer como leitor e crítico para, assim, determinar o valor histórico da literatura de uma época. Candido demostra que o trabalho de historiar a literatura não pode estar separado do exercício crítico, pelo contrário, qualquer estudo sobre literatura deve procurar um equilíbrio entre "história e estética, forma e conteúdo, erudição e gosto, objetividade e apreciação [para demostrar que estas falsas incompatibilidades] são partes de uma explicação tanto quanto possível total" (1993, p. 29, v. 1). Assim, a Formação da Literatura Brasileira soluciona o problema do historiador da literatura, entre objetividade e subjetividade, entrelaçando a valorização do leitor especializado ou crítico literário com a rigorosidade sistêmica do historiador.

Na Formação o leitor encontra-se com juízos que muitas vezes desvalorizam as obras ou os escritores, ao caracterizá-los com termos como medíocre, fraco, pobre, que parecem muito subjetivos. Esses juízos mostram, de um lado, a valorização crítica das obras, própria do labor de Candido como crítico literário, e de outro, certa objetividade na escolha dos autores e das obras, pois o crítico parece não interessar-se se o escritor ou a obra incluída na sua historia literária é ou não de seu afeto, se é boa ou má. 0 importante é a função que cumprem na constituição da literatura brasileira como fato cultural configurado.

Essa avaliação de significado e valor encontra-se, para o autor, na função que determinada obra cumpre na série literária do presente, na relação com séries do passado ou com a tradição, e na maneira como pode influir em obras posteriores. É nesse processo de valoração da obra que o estudo histórico adquire relevância em correspondência com o trabalho crítico. Essa correlação entre séries literárias e o movimento dialético e entre crítica e história literária originam um conceito chave na Formação da Literatura Brasileira, a noção de sistema:
Neste sentido, os escritores brasileiros que, em Portugal ou aqui, escrevem entre, digamos, 1750 (inicio da atividade literária de Cláudio) e 1836 (iniciativa consciente de modificação literária, com a Niterói), tais escritores lançaram as bases de uma literatura brasileira orgânica, como sistema coerente e não manifestações isoladas. Uns foram grandes espíritos, como os "mineiros", Souza Caldas, Jose Bonifácio, Hipólito da Costa; outros, medianos repetidores ou pobres literatos provincianos. Em conjunto porém, a sua passagem pela literatura foi não apenas fecunda e necessária, como em muitos casos, cheia de beleza. (CANDIDO, 1993, p. 67, v. 1)

Por isso, o trabalho de Candido faz ressonância dos postulados de Tinianov, o qual, em Da evolução literária, já expõe a necessidade de pensar que "a obra literária constitui-se num sistema e que a literatura igualmente se constitui em outro" (1927, p.107). Do mesmo modo, o valor de qualquer fenômeno literário está determinado pela função que este cumpre, como elemento de um sistema, em ligação com os outros elementos do mesmo sistema, neste caso, a obra, e com o sistema inteiro, ou seja, com a literatura.

A proposta de sistema na Formação da Literatura Brasileira parece ir além dos postulados de Tinianov, pois o crítico utiliza o termo para pensar a literatura não como um sistema isolado e autônomo, mas como um sistema constituído e articulado com a sociedade, que depende "da existência do triângulo autor-obra-público, em interação dinâmica, e de uma certa continuidade da tradição" (CANDIDO, 1993, p. 16 Vol. 1). Novamente Candido antecipa-se às propostas de Jauss (1967), ao inserir o leitor como elemento ativo na configuração da literatura como sistema, pois é este quem finalmente determina se a obra articula-se com a sociedade, ou como diz Jauss, se responde ao horizonte de expectativas da época.

Resumidamente, o conceito de sistema opera no sentido de síntese da relação, antes dicotômica, do crítico com o historiador literário, já que a visão do crítico é imprescindível para determinar o diálogo entre a obra e o leitor, e posteriormente sua articulação com a sociedade; assim como o trabalho do 
historiador da literatura é preciso para estabelecer as ligações de uma obra com a série de sua época e com a série do passado ou da tradição.

Paralelo ao conceito de sistema está a ideia de influência, que serve a Candido para estabelecer ligações entre os autores e as obras. Além das razões estéticas, essas ligações fazem referência às questões pessoais, como amizade entre os escritores, formação de grupos de intelectuais ou apoio nas publicações. $\mathrm{O}$ fato de traçar os vínculos entre um autor ou obra com outras assegura um movimento de continuidade entre os períodos trabalhados. Embora ele mesmo explique que empregar este termo é problemático pela "dificuldade em distinguir coincidência, influência e plágio" (CANDIDO, 1993, p. 36, v. 1), é útil porque permite encontrar a coerência entre as produções literárias, e entre uma fase, uma corrente ou um grupo.

Uma das figuras que o autor ressalta como influente no processo de formação da literatura nacional é Cláudio Manuel da Costa. No marco do Arcadismo, o escritor, estimulou a Alvarenga Peixoto e Gonzaga no caminho da poesia. Também exerceu influência em escritores posteriores, como Januário da Cunha Barbosa e Natividade Saldanha, ambos foram leitores e, consequentemente, seus seguidores. Já na primeira fase do Romantismo, Candido ressalta a presença de Gonçalves Dias em comparação à função e à importância que representou a figura de Cláudio no início de uma literatura articulada, pois Gonçalves Dias “contribui ao lado de José de Alencar para dar à literatura, no Brasil, uma categoria perdida desde os árcades maiores e, ao modo de Cláudio Manuel, fornece aos sucessores o molde, o padrão a que se referem como inspiração e exemplo" (CANDIDO, 1993, p. 71, v. 1). E na fase final do Romantismo, José de Alencar se converterá na figura mais definida do Romance e até da crítica literária, influenciando grandes escritores, entre eles, Machado de Assis.

Na mesma linha, Candido emprega a noção de sistema para justificar a escolha dos períodos de sua história literária. A Formação da Literatura
Brasileira inicia no período do Arcadismo, não porque esse seja sua origem, mas porque só no século XVIII as manifestações literárias adquiriram características orgânicas de um sistema. Uma das primeiras razões para pensar nos inícios da sistematização da literatura brasileira é o caráter associativo da época, "os letrados tendiam a reunir-se em agrupamentos duradouros ou provisórios, - seja para cumprimento a longo prazo de um programa de estudos e debates literários, seja para comemorar determinado acontecimento" (CANDIDO, 1993, p. 73, v. 1). Estas agremiações formaram uma atmosfera literária que promoveu a consolidação de ideias comuns e a formação de um público leitor, que começam a definir uma articulação dos fatos literários. Além disso, "os grêmios permanentes consagraram atenção marcada às coisas do Brasil, reforçando o nativismo e contribuindo para despertar o sentimento nacional" (CANDIDO, 1993, p. 75, v. 1), o que favoreceu a aparição de uma consciência nacional, a qual somente se consolidará no Romantismo.

Além do caráter associativo adquirido pela literatura brasileira no Arcadismo, o autor destaca uma série de contradições que apoiam ainda mais a configuração de sistema literário. No Arcadismo desenvolve-se grande parte do ideal do homem natural, que "fosse simultaneamente espontâneo e polido, simples e requintado, rústico e erudito, razoável o sentimental" (CANDIDO, 1993, p. 57, v. 1) e cujas preocupações se debatiam entre a harmonia ou desarmonia da natureza, projetadas à harmonia e desarmonia do universo social, ou seja, da sociedade civil. Essas oposições situam o escritor da época numa encruzilhada; de um lado, procuravam o conhecimento da realidade local e a valorização das populações aborígines; de outro lado, pretendiam contribuir para o progresso do país, com a incorporação aos padrões europeus.

O interesse por contribuir para o progresso do país implicava posicionar a literatura brasileira ao mesmo nível das grandes literaturas, ou seja, das 
literaturas já constituídas em sistema. "Os escritores neoclássicos são quase todos animados do desejo de construir uma literatura como prova de que os brasileiros eram capazes quanto os europeus" (CANDIDO, 1993, p. 26, v. 1), de modo que eles seguiam e até imitavam os padrões da literatura do Ocidente, e em particular da literatura portuguesa. Por isso, Candido sustenta que a literatura brasileira "é ramo da portuguesa" (1993, p. 28, v. 1), fenômeno que para o crítico não é negativo, pois a consideração da influência da literatura portuguesa na brasileira favorece sua constituição em sistema, por ter um antecedente, assim como um motivo para gerar renovações. Além disso, situa aos escritores num movimento dialético entre nativismoestrangeirismo, sentimentalismo-realidade, utilitarismo-gratidão, dando um sentido mais orgânico e complexo à literatura da época.

Por exemplo, no caso de Cláudio Manuel da Costa, o autor defende que a importância de sua figura está no fato de que há uma constante na sua obra: "o relativo dilaceramento interior, causado pelo contraste entre o rústico berço mineiro e a experiência intelectual e social da Metrópole, onde fez os estudos superiores e se tornou escritor" (CANDIDO, 1993, p. 85, v. 1). A obra de Cláudio é contemplada, por Candido, precisamente devido essa dicotomia. De um lado, propenso a manter as normas estéticas e os conceitos líricos, sugeridos pela Europa; e de outro lado, ligado com o Brasil, pela fidelidade afetiva com seu lugar de origem. Além disso, Cláudio revela um desejo na sua obra: "fundar uma literatura que significasse a incorporação do Brasil à cultura do Ocidente" (CANDIDO, 1993, p. 102, v. 1).

Nesse interesse generalizado dos escritores da Arcádia, de incorporar o Brasil na cultura europeia, o autor observa novamente um movimento dialético. Situa Basílio da Gama no extremo oposto de Cláudio, com respeito à função que cada um desempenhou na busca daquela incorporação. "Enquanto Cláudio trazia ao Brasil a disciplina clássica, Basílio da Gama, sem transgredi-la, mas nela se movendo com maior liberdade estética e intelectual, levava a Europa o testemunho do mundo novo" (CANDIDO, 1993, p. 127, v. 1).

Portanto, em consonância com sua perspectiva dialética, Candido valoriza como momentos de plenitude aqueles nos quais há uma harmonização ou equilíbrio entre elementos opostos. No caso do Arcadismo, a harmonização entre a forma racional e os impulsos da emoção, expressão ampla do homem natural, e o equilíbrio entre o local e o universal representam o aporte mais significativo para a formação da literatura brasileira como sistema.

Neste cenário dialético, se para o crítico há momentos decisivos ou momentos de plenitude, também há momentos de decadência. Estes ocorrem, no caso do Arcadismo, quando as tendências entram na rotina. E é essa decadência a que permite o surgimento do período Pré-romântico que fará antessala ao Romantismo. Encontramos nesta ideia de Candido uma visão um tanto tradicional da história literária, na qual o fato literário é considerado análogo a um processo biológico, e, portanto, nasce e desenvolve-se para alcançar momentos de resplendor, mas logo vai decaindo até desaparecer, porque depois é superada pelo movimento posterior, neste caso pelo Romantismo. Esta consideração desestabiliza um pouco a concepção de história como processo e continuidade, própria da ideia da literatura como sistema, pois pensar em termos de decadência envolve ruptura e desarticulação no decorrer da história da literatura.

Candido faz várias alusões à decadência do Arcadismo, e à aparição do Romantismo como movimento que supera ao precedente, transformando a poesia, criando o romance, a crítica e a vida literária moderna no Brasil; contudo, a ideia de uma continuidade entre os movimentos segue sendo defendida. Para não deixar cair o Arcadismo no fundo do abismo, Candido caracteriza o período de decadência dessa escola literária como uma fase de transição. Esse período transicional está determinado por, novamente, um movimento dialético entre a tradição Arcádica e novos estilos na poesia. 
Borges de Barros é talvez o escritor mais relevante neste processo. $\mathrm{O}$ autor considera que "A Flor Saudade média entre os poemas arcádicos de um Vilela Barbosa e as melodias plangentes do futuro; verdadeiro eixo em torno do qual gira toda uma transformação literária, ponto inicial duma linha poética fadada ao êxito mais duradouro" (CANDIDO, 1993, p. 270, v. 1).

Além da abertura para pensar numa continuidade, produto do jogo dialético entre tradição e novidade, na citação anterior, Candido oferece-nos uma expressão que considero mais oportuna que a de decadência ou reforma, refiro-me à transformação literária. 0 termo decadência sugere desaparição e ruptura; enquanto reforma refere-se a reparar ou melhorar, como se o que se tinha fosse errado. Transformação, por sua vez, implica mudança ou variação, sem desconhecer o anterior, deixando parte do produto passado e gerando assim continuidade.

As anteriores ambiguidades em torno dos conceitos e das formas nas quais o crítico aborda a transição dos períodos que compõem sua história literária, são mostra de uma nova relação dialética: continuidade e ruptura. Ligação que está determinada pelo conhecimento e consciência da existência de uma tradição e a capacidade de integrar o texto literário ao presente. É precisamente a necessidade dessa ideia de tradição, na conformação do sistema literário, que justifica a apresentação do Arcadismo como momento literário delineador das bases para a consolidação do sistema literário brasileiro. E a literatura no Romantismo é a que finalmente consegue dar continuidade à tradição arcádica, gerando também ruptura com a articulação do texto literário ao presente. No prefácio da segunda edição, Candido já antecipa essa ligação problemática afirmando que:

Há uma solidariedade estreita entre os dois períodos que estudei, pois se a atitude estética os separa radicalmente, a vocação histórica os aproxima, constituindo ambos um largo movimento, depois do qual se pode falar em literatura plenamente constituída. (CANDIDO, 1993, p. 16, v. 1)
Essa caracterização ambígua e complexa da relação entre o Arcadismo e o Romantismo mantém-se durante o desenvolvimento da segunda parte da Formação da literatura brasileira, pois, o Romantismo se debate entre "um momento harmonioso e íntegro" que merece a bajulação do autor como o período mais brasileiro e mais autêntico dos que tiveram; e um momento "marcado por nítida dubiedade nas atitudes e na prática, pois ainda um pouco neoclássicos, são por vezes românticos com reservas mentais" (CANDIDO, 1993, p. 41, v. 2). No entanto, mais do que o caráter dicotômico do período, o que interessa a Candido, neste ponto, é o vínculo que a literatura consegue com a coisa pública, em correspondência com a vontade consciente de ter uma literatura nacional e definida.

O importante nesse jogo de ruptura e continuidade, desenhado por Candido, entre o Arcadismo e o Romantismo é que neste último consolidamse vários desejos e interesses vislumbrados e iniciados no Arcadismo. Por isso, o grande protagonista da história da literatura brasileira para Candido é o Romantismo, pois este movimento converteu-se na materialização da noção de literatura como sistema, porque atuou num país independente, com uma dinâmica cultural mais forte; em comparação com a do Arcadismo, pela criação de bibliotecas, associações científicas e literárias, tipografias, jornais, revistas e teatros. Além do surgimento da crítica literária, junto com a formação de uma teoria nacionalista da literatura e o estudo sistemático do passado literário, propiciado pelas revistas literárias, como a Minerva Brasiliense (1843-1845) e a Guanabara (1851-1855).

De modo que o movimento do Romantismo representou a inserção da literatura brasileira como sistema definido no sistema mais amplo da sociedade. Propósito último de Candido com a sua proposta de literatura como sistema. Por um lado, o campo literário configura-se num sistema que não consta mais de produções isoladas, mas sim da atividade regular de um conjunto numeroso de escritores, exprimindo-se através de veículos que 
asseguram a difusão das obras. Além disso, no Romantismo os escritores reconhecem que, a despeito das influências estrangeiras, já podem ter como ponto de referência uma tradição local. Por outro lado, "o Romantismo no Brasil foi episódio do grande processo de tomada de consciência nacional, constituindo um aspecto do movimento de independência. Afirmar a autonomia no setor literário significava cortar mais um liame com a mãe Pátria" (CANDIDO, 1993, p. 281, v. 1).

Ao parecer, para o autor a prova do amadurecimento da literatura brasileira é a obra de Machado de Assis, e digo "ao parecer" porque é precária a atenção que Candido dá ao escritor e crítico. Machado somente é mencionado para estabelecer comparações com os romancistas que, segundo Candido, sobressaem no Romantismo, mas a escassa referência ao escritor é bastante significativa, como na seguinte passagem:

Uma literatura só pode ser considerada madura quando experimenta a vertigem de tais abismos. Na brasileira, experimentou-a intensamente Machado de Assis, dando-lhe, por esta forma, razão de ser num plano supranacional. (CANDIDO, 1993, p. 193, v. 2)

De fato, Antonio Callado (1992) em artigo dedicado à Formação da Literatura Brasileira manifesta que Machado de Assis é o herói da história literária de Candido, "herói oculto ou semi-oculto, preservado com astúcia e mestria. As qualidades desse herói são amealhadas, entesouradas, e se distribuem, ao longo da narração, com parcimônia, para que o herói surja, quando surgir, em sua completa e indiscutível glória" (CALLADO, 1992, p. 142). 0 próprio Candido declara no prefácio à primeira edição que foi uma falha a exclusão de Machado de Assis, mas que o fez para não seccionar uma obra merecedora de seu estudo como unidade. Consequentemente, o leitor que ficar com incerteza a respeito do lugar que Machado de Assis ocupa no pensamento do crítico, depois dos reduzidos, porém aduladores comentários na Formação da Literatura Brasileira, a solução é encaminhar-se a outras obras de Candido, onde se dá lugar especial a Machado, como na Iniciação à literatura brasileira (1999). Trabalho em que, como extensão da Formação da literatura brasileira, se valora a obra de Machado como representante do sistema literário consolidado:

Machado de Assis era dotado de raro discernimento literário e adquiriu por esforço próprio uma forte cultura intelectual, baseada nos clássicos mas aberta aos filósofos e escritores contemporâneos.[...] Sua obra é variada e tem a característica das produções eminentes: satisfaz tanto aos requintados quanto aos simples. Ela tem, sobretudo, a possibilidade de ser reinterpretada à medida que o tempo passa, porque, tendo uma dimensão profunda de universalidade, funciona como se se dirigisse a cada época que surge.[...] Um dos traços salientes da narrativa de Machado de Assis é o afastamento das modas literárias, que lhe permitiu grande liberdade no tratamento da matéria. Ele é um continuador sui generis de Joaquim Manuel de Macedo e José de Alencar, quanto ao tipo de sociedade incorporada à ficção. Mas se afasta deles na qualidade do estilo e na singularidade do olhar. A sua linguagem não tem a banalidade de um, nem a ênfase do outro: tem a simplicidade densa que é produto extremo do requinte e a fascinante clareza que encobre significados complexos, de difícil avaliação. (CANDIDO, 1999, p. 53-54)

Ainda que na Formação não se ofereça, como no trabalho nomeado, uma explicação ampla da função do Machado de Assis no sistema literário brasileiro, Antonio Candido fecha seu estudo da história literária com umas palavras do escritor, mas em sua faceta de crítico. Segundo o autor, com o ensaio Instinto de Nacionalidade (1873), Machado de Assis se converte no primeiro escritor que teve noção exata do processo literário brasileiro, pois faz um balanço das tendências nacionalistas, sobretudo o indianismo, mostrando que a absorção nos temas locais foi um momento superado, e que a verdadeira literatura depende não do registro de aspectos exteriores e modismos sociais, mas da formação de um "sentimento íntimo" que, embora fazendo do escritor um homem "do seu tempo e do seu país", assegure a sua universalidade. (CANDIDO, 1993; 1999). 
Com certeza, o fechamento da Formação da literatura em voz de Machado de Assis tem um propósito. Nele se revela o interesse de Candido por deixar claro que a obra de Machado de Assis é prova de uma nova fase do sistema literário brasileiro. Uma fase que será posterior á configuração da literatura brasileira como sistema, e que abre as possibilidades de novas aproximações historiográficas com uma seleção periódica mais ampla do que esta.

Só resta dizer, a modo de conclusão, que a proposta de história literária de Candido como formação propõe uma série de pressupostos teóricos inovadores em torno da noção de literatura e de história, produto da tensão de um pensamento orgânico carregado de uma tradição variável de historiadores literários - e digo variável, porque como foi demonstrado nas primeiras páginas, os antecedentes de Candido são bem distintos um do outro-, em diálogo com as exigências teóricas e metodológicas de seu presente. Esse jogo dialético do pensamento de Candido fundamenta toda a construção e escrita da Formação da literatura brasileira, pois as escolhas dos períodos, dos autores e das obras estão justificadas na relação dialética que eles revelam.

De outro lado, é de vital importância nesta obra a inserção da literatura como sistema integrado no sistema cultural, social e até político do país, porque dá um lugar relevante aos estudos de teoria, crítica e história literária, no sentido que começam a ser reconhecidos nos estudos sociais como construtores de significado da sociedade. Desse modo, considero que, embora Candido esforça-se por não inclinar-se a só uma tendência de abordagem do fenômeno literário, a totalidade de sua história da literatura brasileira termina muito perto da corrente sociológica. Uma vez que, como vimos no decorrer do trabalho, a literatura para Candido só adquire sentido quando consegue se integrar ou articular ao sistema social, e de certa maneira quando essa integração implica uma influência dos textos literários na conformação da sociedade.

\section{Referências}

CANDIDO, Antonio. Formação da Literatura Brasileira. 7. ed. Belo Horizonte-Rio de Janeiro: Editora Itatiaia, 1993. $\overline{1999}$

DE ABREU, Mirhiane Mendes. Do ensaio à história literária: o percurso intelectual de Ronald de Carvalho. Remate de Males, Unicamp, v. 27, n. 2, p. 265-275, dez. 2007.

D'INCAO, Maria Angela; SCARABÔTOLO, Eloisa (Orgs.). Dentro do texto, dentro da vida. Ensaios sobre Antonio Candido. São Paulo: Companhia das Letras, Instituto Moreira Salles, 1992.

JAUSS, Hans Robert. A História da literatura como provocação à Teoria Literária. São Paulo: Ática, 1994.

PEDROSA, Celia. Antonio Candido: A palavra empenhada. São Paulo: Editora da Universidade de São Paulo, 1994.

POULIQUEN, Hélène. Una historia de la literatura para un nuevo lector. Literatura: teoría, historia, crítica, Bogotá, n. 8, p. 381-395, 2006.

SOUZA, Roberto Acízelo de. Formação da teoria da literatura. Rio de Janeiro: Ao Livro Técnico, 1987.

TINIANOV, Yuri. Da evolução literária. In: EIKHENBAUM, B. et al. Teoria da literatura. Formalistas russos. Porto Alegre: Globo, 1973. p. 105-118.

VIANA, Sandro. José Veríssimo: Tendências e tensões na escrita da História da Literatura Brasileira. 2005. 105f. Dissertação (Mestrado em Letras) - Fundação Universidade Federal do Rio Grande, Rio Grande.

Recebido em 16/04/2015 Aceito em 21/05/2015, 